\title{
The Possibilities of Chronic Renal Failure Patients Contracting Occult Hepatitis B Virus Infection, Sudan
}

\author{
Elhadi Abdalla Ahmed ${ }^{*}$ (1), Abdelrahman Eldaw Mohammed ${ }^{1}$, Bakri Yousif Mohamed Nour ${ }^{2}$, \\ Albadawi Abdelbagi Talha2,3, Zienab Hamid', Mubarak Ahmed Elshafia', \\ Mohamed Elamin Salih ${ }^{5}$
}

\begin{abstract}
${ }^{1}$ Department of Medical Microbiology, Faculty of Medical Laboratory Sciences, University of Gezira, Wad Medani, Sudan ${ }^{2}$ Department of Medical Parasitology, Faculty of Medical Laboratory Sciences, University of Gezira, Wad Medani, Sudan ${ }^{3}$ Department of Clinical Laboratory Sciences, College of Applied Medical Sciences, Al Jouf University, Sakakah, KSA ${ }^{4}$ Department of Haematology and Immunohaematology, Faculty of Medical Laboratory Sciences, University of Gezira, Wad Medani, Sudan ${ }^{5}$ Department of Surgery, Faculty of Medicine-AlQunfudtha, Umm Al-Qura University, Mecca, KSA Email: *hadilabone@yahoo.com
\end{abstract}

How to cite this paper: Ahmed, E.A., Mohammed, A.E., Nour, B.Y.M., Talha, A.A., Hamid, Z., Elshafia, M.A. and Salih, M.E. (2022) The Possibilities of Chronic Renal Failure Patients Contracting Occult Hepatitis B Virus Infection, Sudan. Advances in Microbiology, 12, 91-102. https://doi.org/10.4236/aim.2022.123008

Received: February 1, 2022

Accepted: March 5, 2022

Published: March 8, 2022

Copyright $\odot 2022$ by author(s) and Scientific Research Publishing Inc. This work is licensed under the Creative Commons Attribution International License (CC BY 4.0).

http://creativecommons.org/licenses/by/4.0/ (c) (i) Open Access

\begin{abstract}
Introduction: Chronic kidney disease (CKD) is a major cause of death in sub-Saharan Africa. The effects of the CKD on the host and the continuous therapeutic measures increase the hypothesis of blood-borne diseases transmission. Objective: This study aimed to find the frequency of occult hepatitis $B$ virus (OBI) in patients of chronic renal failure (CRF) and to study the possibilities of infection acquisition. Methods: During 2017 and 2019, two hundred CRF patients under regular haemodialysis and attending Gezira Hospital for Renal Diseases and Surgery were recruited. Plasma specimens were collected and used for detection of hepatitis B surface antigens (HbsAg), total hepatitis B core antibodies (anti- $\mathrm{HBc}$ ) and hepatitis B virus DNA isolation. Nested PCR reaction was followed to identify HBV. Socio-clinical data for each participant was obtained. Results: Male patients represented 64\% (128/200), most frequent age group was from 41 to 60 years with percentage of 56.5\% (113/200), 86\% (172/200) of CRF patients were received blood while $42 \%$ $(84 / 200)$ get HBV vaccination. Hepatitis B core antibodies were found in $54 \%$ $(108 / 200)$ of studied cases, and $22 \%(42 / 188)$ of tested DNA were positively amplified for target gene. Detection of Hepatitis B core antibodies was significantly associated with marital status while absence of vaccination significantly associated with the detection of both hepatitis $\mathrm{B}$ core antibodies and HBV DNA. Conclusion: This study found high frequency of OBI in CRF patients, to reduce the transmission of the disease, possible hypotheses should be studied, including blood transfusion, haemodialysis process and HBV vac-
\end{abstract}


cination status.

\section{Keywords}

Chronic Renal Failure, OBI, Nested PCR, Sudan

\section{Introduction}

The steady increase in cases of chronic kidney failure (CKD) in developing countries has a tremendous impact on health and economic output [1]. Where it can be said that the continuous medical intervention for patients with CKD, such as hemodialysis, has proven to have many side effects, such as the hypothesis of transmission of blood-stream infections [2]. Cases of people undergoing hemodialysis are increasing worldwide due to the spread of underlying diseases such as diabetes mellitus, hypertension and environmental pollutants [3] [4]. In Sudan, chronic glomerulonephritis, obstructive nephropathy and autosomal dominant poly-cystic kidney diseases are also observed as risk factors among CKD patients [5]. Several reasons have an impact on the emergence of the problem of kidney failure, including the loss of interaction due to the spread of infectious diseases [6] and changes in lifestyle such as rapid urbanization [7]. We also cannot ignore the findings of some studies that determined that race lack of an organized chronic disease management program may affect the epidemiology of kidney failure [8].

Hepatitis B virus (HBV) infection is a global health dilemma with approximately 296 million chronically infected individuals by 2019 [9], and during the past five decades, developing countries remained the most endemic regions [10]. Sero-positivity as an indicator of HBV spread was found to be high in Sudan especially in Gezira State [11]. Generally, HBV infection is diagnosed by the presence of HbsAg in the blood; which is an outer protein expressed in excess when the virus replicates in the liver. However, existence of HBV genome in human even without HBsAg known as occult HBV infection (OBI) [12] [13]. Cases of OBI may have the presence or absence of hepatitis $B$ virus antibodies; anti-hepatitis B core antibody (anti- $\mathrm{HBc}$ ) and anti-hepatitis B surface antibody (anti-HBs) [14].

Conventionally, $\mathrm{HBV}$ is diagnosed by serological techniques to detect antigens or antibodies. The HBsAg is often used for routine diagnosis since it is considered as the hallmark of infection. During acute infection, anti- $\mathrm{HBc}$, initially both IgM and IgG, appear 1 - 2 weeks after the appearance of $\mathrm{HBsAg}$, while IgG persists during chronic infection. In the formulation of immunological concepts the presence of anti-HBs represents response to HBV infection [15]. In the advent of molecular diagnostics, it has been shown that a number of individuals may harbor DNA of HBV at very low levels in their liver and/or serum despite the absence of detectable HBsAg by currently available assays [16]. In line, a study said that infection with the virus is limited in the case of presence of DNA in people 
who carry anti-hepatitis B core antibodies, but the transmission hypothesis remains, as in the case of blood transfusion [2]. Methods for screening of OBI by DNA detection are essential when HBsAg is absent, thus, its consider as golden standard for diagnosis. Commonly used techniques are, real-time PCR, transcription based mediated amplification (TMA) and nested-PCR [17].

Hepatitis $\mathrm{B}$ and $\mathrm{C}$ are the most important liver problems in end stage renal failure patients undergoing hemodialysis and with varying prevalence between countries and even between different dialysis units in the same country [18]. In a North American study, the prevalence of occult hepatitis B virus in adults undergoing dialysis is four to five times higher than the results of positive HBsAg results [19]. Patients undergoing haemodialysis have a potential increase risk of both HBV and OBI; impaired host immune response, multiple transfusion requirements, shared dialysis equipments, invasive procedures that they undergo and low response rates to $\mathrm{HBV}$ vaccination are the main predictors of OBI transmission in such situations [4]. In spite of that, haemodialysis units in Sudan trying to follow the globally acclaimed renal authorities for management of patients including control of hepatitis viruses, a significant deviation in performance had been observed [20]. Some of the followed procedures include regular screening and allocating dialysis units for HBV patients, but It can be said that the viral screening protocol does not include OBI, thus the current study aimed to find out, in Gezira Hospital for Renal Disease and Surgery, the frequency of OBI and HBV DNA using serological and molecular methods, and to highlight existing risk factors.

\section{Methods}

\subsection{Ethical Considerations}

Ethical approval was obtained from the Ministry of Health in Gezira State and Faculty of Medical Laboratory Sciences, University of Gezira, Sudan. All study participants informed by the study objectives and written consents were taken. The confidentiality of result was secured by use of correspondence codes rather than written participant's name. The results were referred to a clinician for appropriate intervention.

\subsection{Study Population and Settings}

This is a cross-sectional laboratory based study, conducted in Gezira Hospital for Renal Diseases and Surgery in Wad Madani city which is the capital of the Gezira State; it lies in the east-central region of the Sudan and it's a well-populated area with a fertile land suitable for agriculture. The period of study was from 2017 to 2019. Participants were 200 patients with chronic renal failure undergoing regular haemodialysis medication and previously recorded as negative for HBV by rapid immunochromatography test (ICT) at the time of study. A validated questionnaire was used to collect demographic and clinical data. The collected data were analyzed using Statistical Package for Social Science (SPSS) ver- 
sion 16, Chi square of $<0.05$ considered significant. Patients with acute renal failure admitted for dialysis were excluded from study subject.

\subsection{Sampling}

Five $\mathrm{ml}$ of venous blood were collected from each participants using sterile syringe and drawn into two EDTA containers. After complete blood clotting plasma samples were separated and kept at $-20^{\circ} \mathrm{C}$ until used.

\subsection{Serological Detection of HBsAg and Anti-HBc}

Test for HBsAg done in Faculty of Medical Laboratory Sciences, University of Gezira using commercial kits, sandwich ELISA (Fortress diagnostics). The absorbance was read using ELISA micro-plate reader (Awareness Technology, Model: 303 PLUS, USA) at wavelength $450 \mathrm{~nm}$, and reference filter at wavelength 630 $\mathrm{nm}$. The cut-off value was calculated to evaluate the results. The electrochemiluminescence immunoassay (ECLIAS) was used to detect total hepatitis B core antibodies (anti-HBc) which qualitatively detect IgG and IgM using full automated cobase 411 machine (Hitachi High-Technology Corporation, Japan) and commercial kits.

\subsection{Viral DNA Isolation}

Phenol chloroform isoamyl alcohol (25:24:1) method was followed for DNA isolation [21]. Five hundred $\mu \mathrm{L}$ of $5 \%$ sodium dodecyl sulphate (SDS) $20 \mu \mathrm{L}$ of proteinase $\mathrm{K}$ were added to $250 \mu \mathrm{L}$ of plasma sample. Mixture was incubated at $56^{\circ} \mathrm{C}$ for one hour and at $95^{\circ} \mathrm{C}$ for 10 minutes. Then, $500 \mu \mathrm{L}$ of phenol chloroform isoamyl alcohol (25:24:1) were added. After centrifugation, the upper layer of mixture was transferred into a new eppendorf tube. In order to obtain sufficient upper layer the last three steps were repeated extra two times. An amount of $20 \mu \mathrm{L}$ of $\mathrm{NaCl} 9 \%$ and $1000 \mu \mathrm{L}$ of cold absolute ethanol were added. The mixture was incubated at $-20^{\circ} \mathrm{C}$ overnight. In the next day, supernatants were discharged after centrifugation to obtain DNA pellet. Tubes were left to dry and washed with $200 \mu \mathrm{L}$ of $70 \%$ ethanol. The tubes were shaken until the pellet disappeared. Finalcentrifuge was made and the supernatants were discharged. Tubes were inverted open for 2 hours and re-suspend in $50 \mu \mathrm{L}$ of sterile distilled water. The DNA was preserved at $-20^{\circ} \mathrm{C}$.

\subsection{Nested PCR for Detection of Hepatitis B Virus}

Nested PCR was done to detect viral DNA of hepatitis B virus using primer pairs (Macrogen, Seoul Korea) as shown in (Table 1). PCR master mix for one reaction mixture using iNtRON'sMaximePCRPreMix (iNTRON biotechnology Soul, Korea) contained $5 \mu \mathrm{L}$ of Taq DNA polymerase, 10XPCR buffer, 10 mMdNTPs and MgCL then $2 \mu \mathrm{l}$ of DNA, $1 \mu \mathrm{L}$ of each $10 \mathrm{P} \mathrm{mol} / \mathrm{ml}$ forward and reverse primer, the volume was completed to $20 \mu \mathrm{L}$ by deionized sterile water. Using PCR system 9700 thermocycler (Singapore) the program initiated with a first denaturation step $95^{\circ} \mathrm{C}$ for $5 \mathrm{~min}$; followed by 30 cycles at $95^{\circ} \mathrm{C}$ for $1 \mathrm{~min}, 56^{\circ} \mathrm{C}$ 
Table 1. Sequences of primers used and expected PCR product sizes [22].

\begin{tabular}{cccc}
\hline Primer direction & Sequence 5'-3' & $T_{m}\left({ }^{\circ} \mathrm{C}\right)$ & size \\
\hline Nested forward & GTTGCCCGTTTGTCCTCTAA & 58.4 & \multirow{2}{*}{ 250 bp } \\
Nested reverse & AAGCCCTACGAACCACTGAA & 58.4 & \\
\hline
\end{tabular}

for $1 \mathrm{~min}, 72^{\circ} \mathrm{C}$ for $2 \mathrm{~min}$, and a final extension at $72^{\circ} \mathrm{C}$ for $5 \mathrm{~min}$. revealed amplicons were visualized in $1.5 \%$ agarose using Cleaver Scientific Ltd. gel documentation system (Model: OMNIDOC). Length of target region showed approximately $250 \mathrm{bp}$.

\section{Results}

\subsection{Demographics of Study Subjects}

In total, 200 haemodialysis patients were enrolled. Male to female ratio equal 1.8:1. Most frequent age group was from 41 to 60 years. Most of studied patients $86 \%(172 / 200)$ had a history of blood transfusion and only $42 \%(84 / 200)$ were $\mathrm{HBV}$ vaccinated. A proportion of cases had a history of surgical intervention and jaundice was $38 \%$ and $28 \%$ respectively (Table 2 ).

\subsection{Sero-Detection of HBsAg and Hepatitis B Core Antibodies}

All participants were previously screened for HBsAg using ICT rapid test and recorded as negative. ELISA method detected HBsAg in 6\% (12/200) of studied subject while hepatitis B core antibodies using ECLIAS resulted in 54\% (108/200) as positive.

\subsection{Molecular Identification of HBV DNA}

Nested PCR was carried out to detect hepatitis B virus DNA among specimens that revealed negative HBsAg. Out of 188 DNA specimens, 22\% (42/188) were successfully amplified using nested primers pairs and yielded approximately band size of $250 \mathrm{bp}$ (Figure 1).

\subsection{Risk Factors Analysis}

Hepatitis B core antibodies was significantly associated with marital status (Chisquare 0.03 ) and with lack of vaccination (Chi-square 0.00 ) in the studied population, while no significant association was found with other observed risk factors (Table 3). Presence of virus DNA has been associated with non-vaccination cases (Chi-square 0.03) among study patients (Table 4).

\section{Discussion}

The most affected by chronic kidney diseases are those who live in sub-Saharan Africa, where most countries with low-income and middle-income are located [23]. Moreover, in the past three decades, the increasing problem of chronic kidney disease and the number of deaths resulting from it has led to its being 
Table 2. Baseline data of CKD participants. No 200.

\begin{tabular}{|c|c|c|c|}
\hline $\begin{array}{l}\text { Socio-clinical } \\
\text { demographic }\end{array}$ & Yes/No & Frequency & Percent \\
\hline \multirow{2}{*}{ Sex } & Male & 128 & 64 \\
\hline & Female & 72 & 36 \\
\hline \multirow{4}{*}{ Age group } & $1-20$ & 5 & 2.5 \\
\hline & $21-40$ & 56 & 28 \\
\hline & $41-60$ & 113 & 56.5 \\
\hline & $61-80$ & 26 & 13 \\
\hline \multirow{2}{*}{ Marital status } & Married & 34 & 17 \\
\hline & Single & 166 & 83 \\
\hline \multirow{2}{*}{$\begin{array}{l}\text { History of blood } \\
\text { transfusion }\end{array}$} & Yes & 171 & 85.5 \\
\hline & No & 29 & 14.5 \\
\hline \multirow{2}{*}{ Alcohol intake } & Yes & 24 & 12 \\
\hline & No & 176 & 88 \\
\hline \multirow{2}{*}{ HBV vaccination } & Yes & 84 & 42 \\
\hline & No & 116 & 58 \\
\hline \multirow{2}{*}{$\begin{array}{c}\text { History of surgical } \\
\text { operation }\end{array}$} & Yes & 76 & 38 \\
\hline & No & 124 & 62 \\
\hline \multirow{2}{*}{ History of jaundice } & Yes & 56 & 28 \\
\hline & No & 144 & 72 \\
\hline \multirow{2}{*}{$\mathrm{HCV}$} & Yes & 0 & 0 \\
\hline & No & 200 & 100 \\
\hline \multirow{2}{*}{ HIV } & Yes & 0 & 0 \\
\hline & No & 200 & 100 \\
\hline
\end{tabular}

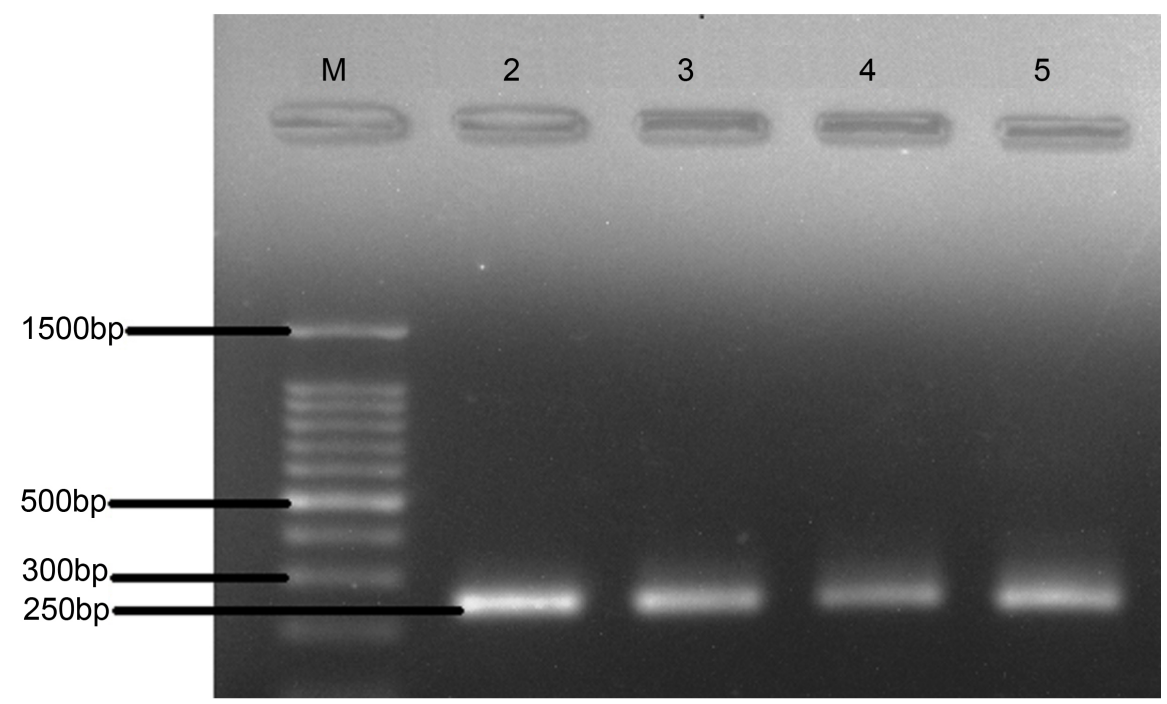

Figure 1. PCR gel presentation of HBV DNA. Lane M 100bp DNA ladder. Lanes 2, 3, 4 and 5 positive cases showing typical band size of $250 \mathrm{bp}$. 
E. A. Ahmed et al.

Table 3. Risk factors associated with hepatitis B core antibodies in study subjects. No 108 .

\begin{tabular}{|c|c|c|c|}
\hline Risk factor & Yes/No & Frequency (\%) & Chi-Square \\
\hline \multirow{2}{*}{ Sex } & Male & $71(65.7)$ & \multirow{2}{*}{0.658} \\
\hline & Female & $37(34.3)$ & \\
\hline \multirow{4}{*}{ Age group } & $1-20$ & $3(2.8)$ & \multirow{4}{*}{0.05} \\
\hline & $21-40$ & $41(38)$ & \\
\hline & $41-60$ & $54(50)$ & \\
\hline & $61-80$ & $10(9)$ & \\
\hline \multirow{2}{*}{ Marital status } & Married & $24(22.2)$ & \multirow{2}{*}{0.03} \\
\hline & Single & $84(77.8)$ & \\
\hline \multirow{2}{*}{$\begin{array}{l}\text { History of blood } \\
\text { transfusion }\end{array}$} & Yes & $90(83.3)$ & \multirow{2}{*}{0.422} \\
\hline & No & $18(16.7)$ & \\
\hline \multirow{2}{*}{ Alcohol intake } & Yes & $10(9.3)$ & \multirow{2}{*}{0.275} \\
\hline & No & $98(90.7)$ & \\
\hline \multirow{2}{*}{ No vaccination } & Yes & $69(63.9)$ & \multirow{2}{*}{0.00} \\
\hline & No & $39(36.1)$ & \\
\hline \multirow{2}{*}{$\begin{array}{l}\text { History of surgical } \\
\text { operation }\end{array}$} & Yes & $35(32.4)$ & \multirow{2}{*}{0.082} \\
\hline & No & $73(67.6)$ & \\
\hline \multirow{2}{*}{ History of jaundice } & Yes & $32(29.6)$ & \multirow{2}{*}{0.637} \\
\hline & No & $76(70.4)$ & \\
\hline
\end{tabular}

Table 4. Risk factors associated with HBV DNA detection in study subjects. No 42.

\begin{tabular}{cccc}
\hline Risk factor & Yes/No & Frequency (\%) & Chi-Square \\
\hline Sex & Male & $31(73.8)$ & 0.201 \\
& Female & $11(26.2)$ & \\
Age group & $1-20$ & $1(2.4)$ & 0.588 \\
& $21-40$ & $11(26.2)$ & \\
& $41-60$ & $22(52.4)$ & 0.503 \\
Marital status & $61-80$ & $8(19)$ & 0.084 \\
History of blood & Married & $9(21.4)$ & \\
transfusion & Single & $33(78.6)$ & 1.000 \\
Alcohol intake & Yes & $32(76.2)$ & \\
& No & $10(23.8)$ & 0.322 \\
\hline History of jaundice & Yes & $5(11.9)$ & \\
\hline No vaccination & No & $37(88.1)$ & 0.473 \\
History of surgical & Yes & $12(28.6)$ & \\
operation & No & $30(71.4)$ & $18(42.9)$ \\
\hline
\end{tabular}


added to the list of the leading causes of death in sub-Saharan Africa along with malaria, tuberculosis and AIDS [24] [25].

More data on the occurrence of OBI in developing world is necessary, especially, in individuals of high risk for HBV due to the limited existent data and diagnostic methods as well as lack of precise prevalence rate. The importance of identifying OBI in patients with chronic kidney failure as a risk group is due to their impaired cellular immunity, undergoing regularly haemodialysis and multiple blood transfusion intervention [26]. Understanding of the occurrence and transmission of OBI among patients with CKD enables knowledge of prevention measures to limit the transmission and spread.

The age group, 41 - 60 years, for CKD participants was the most frequent, which is similar to what is published in sub-Saharan Africa [27]. Although this study did not focus on determining hemoglobin levels, anemia is a common dilemma among patients with chronic kidney failure [28] [29], since most of the participants in this study had undergone blood transfusions. In many reports, the global prevalence of OBI varies from 0 - 58\% [30] [31], our study revealed $22 \%(42 / 188)$ had positive OBI; it could be because most of participants had undergone multiple blood transfusion. Furthermore; the lack of diagnostic methods to identify the OBI in the blood of donors, its transmission is possible and subsequently, increases with the frequency of blood transfusions. Similarly, high rates of OBI among haemodialysis cases were reported in Egypt [14], but low and high rates were also documented in the same country as showed in [32] [33] [34] [35]. Despite the implementation of effective vaccination programs, hepatitis B remains an important cause of morbidity and mortality worldwide.

Considering the studies that indicated vaccination against hepatitis $B$ virus for those suffering from CKD [36] [37], the proportion of unvaccinated included CRF patients in the study is of concern. Therefore, we found significant association between the presence of hepatitis B core antibodies, HBV DNA and the absence of vaccination. It is also important to monitor the levels of protective antibodies formed as a result of vaccination, as the protection resulting from vaccination may reach only $85 \%$, in addition to the fact that the effectiveness of vaccination has not been confirmed for life [38]. Furthermore, with some cases, protection against HBV may require booster doses [39]. From the current study, immune chromatography test was less sensitive method for detection of HBsAg comparing to ELISA which was strongly supported by [40] in India. The detection of the virus by both mentioned tests was previously reported as failed due to mutations in the $S$ gene which may lead to structural changes in HBsAg [41]. It should be noted that, variation in the sensitivity of serological diagnostic methods is likely to indicate the extent of these mutations. These observations may justify the high prevalence of OBI due to lack of knowledge, attitudes about HBV vaccination, modes of transmission, its consequences, its preventive measures, the improvement in diagnosis and documentation of HBV infection. The discrepancy in the reported incidences of HBV from different parts of Sudan [11] 
[42] [43] justifies conduction of further studies to consider other risk factors like race, social and health status and, provision of health services. Limitation of $\mathrm{HB}$ vaccination program in Sudan and targeting of other high risk groups such as medical personnel also may contribute to continuous increasing in HBV infection especially among CKD individuals.

\section{Conclusion}

The acquisition of OBI for studied patients with CKD may be due to the lack of vaccination, the continuation of the haemodialysis process and consequent procedures and, multi-blood transfusion intervention. Thus, monitoring of CKD patients by regular screening of OBI is strongly recommended.

\section{Limitation of Study}

This study did not classify patients by stages of chronic renal failure or duration of dialysis intervention. Furthermore, detected genes of HBV were not characterized by sequencing analysis.

\section{Acknowledgements}

The authors would like to thanks staff of Gezira Hospital for Renal Diseases and Surgery in Wad Madani city for help and support during study periode, and all technicians work in the Medical Laboratory of the hospital.

\section{Conflicts of Interest}

The authors declare no conflicts of interest regarding the publication of this paper.

\section{Data Availability}

Data of this study can be obtained from the correspondent author.

\section{References}

[1] Talbot, B., Athavale, A. and VivekanandJha, G.M. (2021) Data Challenges in Addressing Chronic Kidney Disease in Low- and Lower-Middle-Income Countries. Kidney International Reports, 6, 1503-1512. https://doi.org/10.1016/j.ekir.2021.03.901

[2] Nguyen, D.B., Arduino, M.J. and Patel, P.R. (2019) Hemodialysis-Associated Infections. In: Chronic Kidney Disease, Dialysis, and Transplantation, Elsevier, Amsterdam, 389-410.e8. https://doi.org/10.1016/B978-0-323-52978-5.00025-2 https://linkinghub.elsevier.com/retrieve/pii/B9780323529785000252

[3] Himmelfarb, J., Vanholder, R., Mehrotra, R. and Tonelli, M. (2020) The Current and Future Landscape of Dialysis. Nature Reviews Nephrology, 16, 573-585. https://doi.org/10.1038/s41581-020-0315-4

[4] Aghakhani, A., Banifazl, M., Velayati, A.A., Eslamifar, A. and Ramezani, A. (2012) Occult Hepatitis B Virus Infection in Hemodialysis Patients: A Concept for Consideration. Therapeutic Apheresis and Dialysis, 16, 328-333. 
https://doi.org/10.1111/j.1744-9987.2012.01072.x

[5] Banaga, A.S.I., Mohammed, E.B., Siddig, R.M., Salama, D.E., Elbashir, S.B., Khojali, M.O., et al. (2015) Causes of End Stage Renal Failure among Haemodialysis Patients in Khartoum State/Sudan. BMC Research Notes, 8, Article No. 502.

https://doi.org/10.1186/s13104-015-1509-x

[6] Nugent, R.A., Fathima, S.F., Feigl, A.B. and Chyung, D. (2011) The Burden of Chronic Kidney Disease on Developing Nations: A 21st Century Challenge in Global Health. Nephron Clinical Practice, 118, c269-c277. https://doi.org/10.1159/000321382

[7] Hove, M., Ngwerume, E.T. and Muchemwa, C. (2013) The Urban Crisis in Sub-Saharan Africa: A Threat to Human Security and Sustainable Development. Stability, 2, 1-14. https://doi.org/10.5334/sta.ap

[8] Abraham, G., Varughese, S., Thandavan, T., et al. (2016) Chronic Kidney Disease Hotspots in Developing Countries in South Asia. Clinical Kidney Journal, 9, 135-141. https://doi.org/10.1093/ckj/sfv109

[9] WHO Fact Sheet 27 July. Hepatitis B. https://www.who.int/news-room/fact-sheets/detail/hepatitis-b

[10] Zampino, R., Boemio, A., Sagnelli, C., Alessio, L., Adinolfi, L.E., Sagnelli, E., et al. (2015) Hepatitis B Virus Burden in Developing Countries. World Journal of Gastroenterology, 21, 11941-1153. https://doi.org/10.3748/wjg.v21.i42.11941

[11] Mudawi, H., Smith, H., Rahoud, S., Fletcher, I., Saeed, O. and Fedail, S. (2007) Prevalence of Hepatitis B Virus Infection in the Gezira State of Central Sudan. Saudi Journal of Gastroenterology, 13, 81-83. https://doi.org/10.4103/1319-3767.32182

[12] Yang, L., Li, T., Li, W., Tang, X., Li, J., Long, R., et al. (2017) Occult Hepatitis B Virus Infection in Hyperlipidemia Patients. The Tohoku Journal of Experimental Medicine, 241, 255-261. https://doi.org/10.1620/tjem.241.255

[13] Zhu, H.-L., Li, X., Li, J. and Zhang, Z.-H. (2016) Genetic Variation of Occult Hepatitis B Virus Infection. World Journal of Gastroenterology, 22, 3531-3546.

https://doi.org/10.3748/wjg.v22.i13.3531

[14] Elbahrawy, A., Alaboudy, A., El Moghazy, W., Elwassief, A., Alashker, A. and Abdallah, A.M. (2015) Occult Hepatitis B Virus Infection in Egypt. World Journal of Hepatology, 7, 1671-1678. https://doi.org/10.4254/wjh.v7.i12.1671

[15] Song, J.E. and Kim, D.Y. (2016) Diagnosis of Hepatitis B. Annals of Translational Medicine, 4, 338. https://doi.org/10.21037/atm.2016.09.11

[16] Gachara, G., Magoro, T., Mavhandu, L., Lum, E., Kimbi, H.K., Ndip, R.N., et al. (2017) Characterization of Occult Hepatitis B Virus Infection among HIV Positive Patients in Cameroon. AIDS Research and Therapy, 14, 11.

https://doi.org/10.1186/s12981-017-0136-0

[17] Ocana, S., Casas, M.L., Buhigas, I. and Lledo, J.L. (2011) Diagnostic Strategy for Occult Hepatitis B Virus Infection. World Journal of Gastroenterology, 17, 1553-1557. https://doi.org/10.3748/wjg.v17.i12.1553

[18] Kosaraju, K., Faujdar, S.S., Singh, A. and Prabhu, R. (2013) Hepatitis Viruses in Heamodialysis Patients: An Added Insult to Injury? Hepatitis Research and Treatment, 2013, Article ID: 860514. https://doi.org/10.1155/2013/860514

[19] Minuk, G.Y., Sun, D.F., Greenberg, R., Zhang, M., Hawkins, K., Uhanova, J., Gutkin, A., Bernstein, K., Giulivi, A. and Osiowy, C. (2004) Occult Hepatitis B Virus Infection in a North American Adult Hemodialysis Patient Population. Hepatology, 40, 1072-1077. https://doi.org/10.1002/hep.20435

[20] Abdelwahab, H., Shigidi, M., El-Tohami, A. and Ibrahim, L. (2013) Adherence of 
Healthcare Professionals to Evidence-Based Clinical Practice Guidelines in the Management of Hemodialysis Patients, Khartoum State, Sudan. Arab Journal of Nephrology and Transplantation, 6, 99-104.

[21] Changotra, H. and Sehajpal, P.K. (2013) An Improved Method for the Isolation of Hepatitis B Virus DNA from Human Serum. Indian Journal of Virology: An Official Organ of Indian Virological Society, 24, 174-179.

https://doi.org/10.1007/s13337-013-0155-y

[22] Amal, G.H., et al. (2017) Molecular Detection and Sero-Frequency Rate of Occult Hepatitis B Virus among Blood Donorsin Southern Darfur State (Sudan). African Journal of Medical Sciences, 2, 1-7.

[23] George, C., Stoker, S., et al. (2021) The Chronic Kidney Disease in Africa (CKDAfrica) Collaboration: Lessons from a New Pan-African Network. BMJ Global Health, 6, e006454. https://doi.org/10.1136/bmjgh-2021-006454

[24] Matsha, T.E. and Erasmus, R.T. (2019) Chronic Kidney Disease in Sub-Saharan Africa. The Lancet Global Health, 7, e1587-e1588. https://doi.org/10.1016/S2214-109X(19)30467-X

[25] George, J.A., et al. (2019) Kidney Damage and Associated Risk Factors in Rural and Urban Sub-Saharan Africa (AWI-Gen): A Cross-Sectional Population Study. The Lancet Global Health, 7, e1632-e1643. https://doi.org/10.1016/S2214-109X(19)30443-7

[26] Bernieh, B. (2015) Viral Hepatitis in Hemodialysis: An Update. Journal of Translational Internal Medicine, 3, 93-105. https://doi.org/10.1515/jtim-2015-0018

[27] Matsha, T.E., Yako, Y.Y., Rensburg, M.A., et al. (2013) Chronic Kidney Diseases in Mixed Ancestry South African Populations: Prevalence, Determinants and Concordance between Kidney Function Estimators. BMC Nephrology, 14, Article No. 75. https://doi.org/10.1186/1471-2369-14-75

[28] Ye, Y., Liu, H., Chen, Y., Zhang, Y., Li, S., Hu, W., Yang, R., Zhang, Z., Lv, L. and Liu, X. (2018) Hemoglobin Targets for the Anemia in Patients with Dialysis-Dependent Chronic Kidney Disease: A Meta-Analysis of Randomized, Controlled Trials. Renal Failure, 40, 671-679. https://doi.org/10.1080/0886022X.2018.1532909

[29] Song, K.K., Zhao, D.L., Wang, Y.D., et al. (2017) Analysis of Factors Associated with Death in Maintenance Hemodialysis Patients: A Multicenter Study in China. Chinese Medical Journal, 130, 885-891. https://doi.org/10.4103/0366-6999.204103

[30] Fontenele, A.M., Filho, N.S. and Ferreira, A.S. (2013) Occult Hepatitis B in Patients on Hemodialysis: A Review. Annals of Hepatology, 12, 527-531. https://doi.org/10.1016/S1665-2681(19)31335-3

[31] Muche, M., Berg, T., Rimpler, S., Staedtler, A., Böhm, S., Nickel, P. and Baid-Agrawal, S. (2019) Low Prevalence of Occult Hepatitis B Virus Infection in Chronic Haemodialysis and Kidney Transplant Patients. Liver International, 39, 263-270.

https://doi.org/10.1111/liv.13951

[32] Ismail, H., Soliman, M. and Nahed Ismail, N. (2010) Occult Hepatitis B Virus Infection in Egyptian Hemodialysis Patients with or without Hepatitis C Virus Infection. Pathology and Laboratory Medicine International, 2, 113-120. https://doi.org/10.2147/PLMI.S12341

[33] Bedewy, K.M.L. and Ibrahim, Y.N. (2006) TT-Virus and Occult Hepatitis B Virus Infections in Egyptian Hemodialysis Patients. Egyptian Journal of Medical Microbiology, 15, 17-26.

[34] Elgohry, I., Elbanna, A. and Hashad, D. (2012) Occult Hepatitis B Virus Infection in a Cohort of Egyptian Chronic Hemodialysis Patients. Clinical Laboratory, 58, 1057-1061. 
[35] El Sayed Zaki, M., Rafaat, D., Eliwa, A. and Abdelsalam, M. (2014) Occult Hepatitis B among Patients under Hemodialysis at Mansoura University Hospitals: Prevalence and Risk Factors. Journal of Virology \&Antiviral Research, 3, 1.

[36] Kidney Disease: Improving Global Outcomes (KDIGO) CKD Work Group (2013) KDIGO 2012 Practice Guideline for the Evaluation and Management of Chronic Kidney Disease. Kidney International, 3, 1-150.

[37] Zitt, E., et al. (2017) Response to Active Hepatitis B Vaccination and Mortality in Incident Dialysis Patients. Vaccine, 35, 814-820. https://doi.org/10.1016/j.vaccine.2016.12.032

[38] Pattyn, J., Hendrickx, G., Vorsters, A. and Van Damme, P. (2021) Hepatitis B Vaccines. The Journal of Infectious Diseases, 224, S343-S351. https://doi.org/10.1093/infdis/jiaa668

[39] Leuridan, E. and Van Damme, P. (2011) Hepatitis B and the Need for a Booster Dose. Clinical Infectious Diseases, 53, 68-75. https://doi.org/10.1093/cid/cir270

[40] Ayodeji, A.O., Ismai'la, A. and Umar, S.F. (2019) Comparative Evaluation of Chromatographic Immunoassay and Enzyme-Linked Immunosorbent Assay in the Diagnosis of Hepatitis B Viral Infection in Pregnancy. ARC Journal of Hematology, 4, 28-34.

[41] Almeida, R.W., et al. (2017) Detection and Molecular Characterisation of a Diagnosis Escape Variant Associated with Occult Hepatitis B Virus in Brazil. Memórias do Instituto Oswaldo Cruz, 112, 485-491. https://doi.org/10.1590/0074-02760160477

[42] World Health Organization (1996) Expanded Program on Immunization, Hepatitis B Vaccine, Making Global Progress: EPI Update. Geneva.

[43] McCarthy, M.C., Hyams, K.C., el-Tigani el-Hag, A., et al. (1989) HIV-1 and Hepatitis B Transmission in Sudan. Aids, 3, 725-729.

https://doi.org/10.1097/00002030-198911000-00006

\section{List of Abbreviations}

CKD: Chronic kidney disease; CRF: chronic renal failure; HBV: hepatitis B virus; OBI: occult hepatitis B virus; HbsAg: hepatitis B surface antigens; anti-HBc: anti-total hepatitis B core antibodies; anti-HBc: hepatitis B core antibody; anti-HBs: anti-hepatitis B surface antibody. 